\title{
ANALYSIS OF FACTORS RELATED TO THE EVENT OF OSTEOPOROSIS IN WOMEN
}

\author{
Jasvirgon', Rachmawaty M.Noer ${ }^{2}$, Mira Agusthya ${ }^{3}$ \\ 1,2,3 Program Studi Ilmu Keperawatan STIKes Awal Bros Batam
}

Email korespodensi: hattorivirgo@gmail.com

\begin{abstract}
Awal Bros Hospital Batam in the last 2 years namely in 2018 there were 14 women and in 2019 there were 23 women who had osteoporosis.Data obtained in the last 2 years, namely in 2018 there were 20 women and in 2019 there were 31 women with osteoporosis. From the information above, there are still many women affected by osteoporosis, but still do not know about the factors that cause osteoporosis itself. This study aims to determine the factors related to the occurrence of osteoporosis in women in Embung Fatimah Regional Hospital Batam Bintan in 2019 on February 27 to March 11,2020 . The design of this study is descriptive quantitative with cross sectional approach with the sampling method in this study. is total sampling. The sample in this study consisted of women with osteoporosis at the Embung Fatimah Regional Hospital in Batam City amounting to 31 people and the data were analyzed using the chi-square test. The results showed that there was a relationship between respondent's knowledge of the incidence of osteoporosis in Embung Fatimah Regional Hospital in Batam City, there was a relationship between respondents 'attitudes toward osteoporosis in Embung Fatimah Regional Hospital in Batam City, there was a relationship between respondents' lifestyle on the incidence of osteoporosis in Embung Fatimah Regional Hospital in Batam City. From the results of the analysis, the determinant coefficient value (Adjusted $\mathrm{R}$ Square) $=0.312$ means that $31.2 \%$ of knowledge, attitude and lifestyle factors can be explained about the incidence of osteoporosis.
\end{abstract}

\section{Keywords : Attitude, Knowledge, Lifestyle, Women}

\section{PENDAHULUAN}

Wanita memiliki resiko osteoporosis lebih tinggi dibanding laki-laki, hal ini dikarenakan wanita mengalami proses kehamilan dan menyusui serta penurunan hormon estrogen pada saat premenopause, menopause, dan pasca menopause. Pada pria juga memiliki resiko terkena osteoporosis, penyakit osteoporosis pada pria juga dipengaruhi oleh hormon. Bedanya laki-laki tidak mengalami menopause, sehingga osteoporosis datang lebih lambat (La Ode, 2016). Peningkatan usia berhubungan dengan peningkatan risiko 
osteoporosis. Seiring dengan meningkatnya usia, pertumbuhan tulang akan semakin menurun. Sel osteoblas akan lebih cepat mati karena adanya sel osteoklas yang menjadi lebih aktif, sehingga tulang tidak dapat digantikan dengan baik dan massa tulang akan terus menurun (Agustin, 2017). Hasil penelitian Prihatini, et al(2010) menyatakan bahwa pada usia kurang dari 35 tahun $5,7 \%$ sampel beresiko osteoporosis dan proporsinya terus meningkat dengan bertambahnya usia. Proporsinya mulai meningkat tajam pada usia 55 tahun. Hasil penelitian Mubaidah dan Hareni (2010) menyebutkan tentang pencegahan osteoporosis dapat dilakukan dengan meningkatkan pengetahuan dari lansia terhadap osteoporosis, sesuai dengan karakteristik yang ditelitinya ditemukan usia yang tua, tingkat pendidikan yang rendah, profesi sebagai petani, dan pengetahuan yang kurang.

Hasil penelitian yang dilakukan oleh Mubaidah dan Hareni (2010), didapatkan bahwa responden memiliki pengetahuan tentang osteoporosis dalam kategori cukup. Penelitian yang dilakukan oleh Yuniar dan Halifah (2016) terdapat sikap negatif terhadap pencegahan osteoporosis, karena dipengaruhi faktor dari lingkungan, pengaruh individu dan proses biologis terhadap pengolahan informasi, pembelajaran, perubahan sikap dan perilaku dan sesuai dengan penelitian yang dilakuan oleh Prihartini, Mahirawati, Jahari, dan Sudiman (2010), bahwa salah satu faktor-faktor risiko osteoporosis adalah riwayat kesesahatan dan gaya hidup, dimana pada gaya hidup terdapat hubungan antara orang yang tidak terbiasa berolaharga dengan suka meminum kopi untuk terkena osteoporosis. Berdasarkan pada saat dilakukan study pendahuluan yang dilakukan peneliti di Rumah Sakit Awal Bros Batam dan RSUD Embung Fatimah Kota Batam. Sebagai data awal dengan didapatkan data di Rumah Sakit Awal Bros Batam pada 2 tahun terakhir yaitu pada tahun 2018 terdapat 14 orang wanita dan pada tahun 2019 terdapat 23 orang wanita yang mengalami osteoporosis. Sedangkan di RSUD Embung Fatimah Batam didapatkan data pada 2 tahun terakhir yaitu pada tahun 2018 terdapat 20 orang wanita dan pada tahun 2019 terdapat 31 orang wanita dengan osteoporosis. Dari informasi diatas masih banyaknya wanita yang terkena osteoporosis, namun masih kurang mengetahui mengenai faktor-faktor 
penyebab osteoporosis itu sendiri, hal ini didukung berdasarkan peneliti mewawancarai 10 orang wanita, dimana 6 orang wanita kurang mengetahui terhadap pencegahan osteoporosis, 6 orang wanita menyikapi kurang baik terhadap pencegahan osteoporosis. Sedangkan 4 wanita lainnya mengatakan sudah mengetahui pencegahan osteoporosis pada saat setelah mengalami osteoporosis. 6 orang wanita mengatakan tentang kebiasaan yang jarang olahraga, 4 orang wanita lainnya sudah menjalankan gaya hidup yang sehat setelah mengalami osteoporosis. Berdasarkan latar belakang diatas penulis tertarik untuk melakukan penelitian dengan judul faktor - faktor yang berhubungan dengan kejadian osteoporosis pada wanita di RSUD Embung Fatimah Kota Batam Tahun 2019.

\section{METODE}

Jenis penelitian yang digunakan pada penelitian ini adalah deskriptif kuantitatif dengan pendekatan cross sectional. Penelitian ini bertujuan untuk menganalisa faktor - faktor yang berhubungan dengan kejadian osteoporosis pada wanita di RSUD Embung Fatimah Kota Batam. Pada penelitian ini sebagai populasinya adalah seluruh wanita yang mengalami osteoporosis di RSUD Embung Fatimah Kota Batam berjumlah 31 pasien. Pada penelitian ini, peneliti menggunakan teknik sampel jenuh atau total sampling yaitu teknik penentuan sampel dengan cara mengambil seluruh anggota populasi sebagai responden atau sampel yaitu 31 orang.

\section{HASIL}

\section{Analisis Univariat}

Tabel 1. Karakteristik Responden Berdasarkan Usia, Pekerjaan dan Pendidikan di RSUD Embung Fatimah Kota Batam Tahun 2019

\begin{tabular}{|c|c|c|c|}
\hline NO & Karakteristik Responden & $\mathbf{f}$ & $\%$ \\
\hline \multirow[t]{5}{*}{1} & Usia & & \\
\hline & a. 45-50 Tahun & 17 & 54,8 \\
\hline & b. 51-65 Tahun & 11 & 35,5 \\
\hline & c. $>65$ Tahun & 3 & 9,7 \\
\hline & Total & 31 & 100 \\
\hline
\end{tabular}


2

Pekerjaan

1. Bekerja

2. Tidak Bekerja

45,2

Total

54,8

3 Pendidikan
a. SD
48,4
b. SMP
32,3
c. SMA
d. D1-S1
Total
31

Tabel 1 di atas dapat dilihat bahwa responden yang dilakukan wawancara sebanyak 31 orang. Usia responden tertinggi adalah yang berusia lebih dari 45-50 tahun sebanyak 17 orang $(54,8 \%)$. Dengan responden tertinggi adalah tidak bekerja dengan jumlah 17 orang $(54,8 \%)$. Dalam penelitian ini, pendidikan responden tertinggi adalah SD sebanyak 15 responden $(48,4 \%)$.

Tabel 2 Distribusi Frekuensi Pengetahuan Responden di RSUD Embung Fatimah Kota Batam Tahun 2019

\begin{tabular}{clccc}
\hline No & Pengetahuan & f & \% \\
\hline 1. & Baik & 3 & 9,7 \\
\hline 2. & Cukup & 5 & 16,1 \\
\hline 3. & Kurang & 23 & 74,2 \\
\hline \multicolumn{2}{r}{ Jumlah } & $\mathbf{3 1}$ & $\mathbf{1 0 0}$ \\
\hline
\end{tabular}

Tabel 2 diatas dapat dilihat bahwa pengetahuan responden di RSUD Embung Fatimah tertinggi yaitu pengetahuan kurang sebanyak 23 orang $(74,2 \%)$ dan terendah yaitu penegtahuan baik adalah 3 orang $(9,7 \%)$.

Tabel 3 Distribusi Frekuensi Sikap Responden di RSUD Embung Fatimah Kota Batam Tahun 2019

\begin{tabular}{clcc|c} 
No & Sikap & f & \% \\
\hline 1. & Positif & & 11 & 35,5 \\
\hline 2. & Netral & & 11 & 35,5 \\
\hline 3. & Negatif & & 9 & 29 \\
\hline & & Jumlah & $\mathbf{3 1}$ & $\mathbf{1 0 0}$ \\
\hline
\end{tabular}

Tabel 3 diatas dapat dilihat bahwa sikap responden di RSUD Embung Fatimah tertinggi yaitu sikap postif dan netral sebanyak 11 orang $(35,5 \%)$ dan terendah yaitu negatif adalah 9 orang $(29 \%)$. 
Tabel 4 Distribusi Frekuensi Gaya Hidup Responden di RSUD Embung Fatimah Kota Batam Tahun 2019

\begin{tabular}{cllc|c} 
No & Gaya Hidup & f & $\mathbf{\%}$ \\
\hline 1. & Sehat & & 15 & 48,4 \\
\hline 2. & Tidak Sehat & & 16 & 51,6 \\
\hline & & Jumlah & $\mathbf{3 1}$ & $\mathbf{1 0 0}$ \\
\hline
\end{tabular}

Tabel 4 diatas dapat dilihat bahwa gaya hidup responden di RSUD Embung Fatimah tertinggi yaitu gaya hidup tidak sehat sebanyak 16 orang $(51,6 \%)$ dan terendah yaitu sehat adalah 15 orang $(48,4 \%)$.

Tabel 5 Distribusi Frekuensi Kejadian Osteoporosis di RSUD Embung Fatimah Kota Batam Tahun 2019

\begin{tabular}{llcc|c} 
No & & Kejadian Osteoporosis & f & \% \\
\hline 1. & Terjadi & & 18 & 58,1 \\
\hline 2. & Tidak Terjadi & & 13 & 41,9 \\
\hline & & Jumlah & $\mathbf{3 1}$ & $\mathbf{1 0 0}$ \\
\hline
\end{tabular}

Tabel 5 diatas dapat dilihat bahwa kejadian osteoporosis di RSUD Embung Fatimah Kota Batam tertinggi yaitu terjadi sebanyak 18 orang $(58,1 \%)$ dan terendah yaitu tidak terjadi adalah 13 orang $(41,9 \%)$.

\section{Analisis Bivariat}

Tabel 6 Hubungan Pengetahuan Dengan Kejadian Osteoporosis Di RSUD Embung Fatimah Kota Batam Tahun 2019

\begin{tabular}{|c|c|c|c|c|c|c|c|c|}
\hline \multirow[t]{3}{*}{ No } & \multirow{3}{*}{ Pengetahuan } & \multicolumn{4}{|c|}{ Kejadian Osteoporosis } & \multirow{2}{*}{\multicolumn{2}{|c|}{ Jumlah }} & \multirow{3}{*}{$\begin{array}{c}\text { Nilai } \\
\text { P value }\end{array}$} \\
\hline & & \multicolumn{2}{|c|}{ Terjadi } & \multicolumn{2}{|c|}{ Tidak Terjadi } & & & \\
\hline & & $\mathbf{n}$ & $\%$ & $\mathbf{n}$ & $\%$ & $\mathbf{N}$ & $\%$ & \\
\hline 1. & Baik & 0 & 0 & 3 & 23,1 & 3 & 9,7 & 0,048 \\
\hline 2. & Cukup & 2 & 11,1 & 3 & 23,1 & 5 & 16,1 & \\
\hline 3. & Kurang & 16 & 69,6 & 7 & 30,4 & 23 & 74,2 & \\
\hline & Jumlah & 18 & 58,1 & 13 & 41,9 & 31 & 100 & \\
\hline
\end{tabular}

Tabel 6 dapat diketahui bahwa dari 31 responden sebagian besar responden pengetahuan baik osteoporosis terjadi ada $0 \%$, hanya $23,1 \%$ yang tidak terjadi dan sebagian besar responden pengetahuan kurang terjadinya osteoporosis ada 69,6\%, hanya $30,4 \%$ yang tidak terjadi. Hasil uji statistik chi-square didapatkan nilai $\mathrm{p}$ value $0,048 \leq 0,05$ berarti dapat disimpulkan berarti dapat disimpulkan ada 
perbedaan proporsi pengetahuan responden yang terjadi osteoporosis dengan yang tidak terjadi osteoporosis, artinya Ho ditolak dan Ha diterima (ada hubungan pengetahuan responden terhadap kejadian osteoporosis di RSUD Embung Fatimah Kota Batam ).

Tabel 7 Hubungan Sikap Dengan Kejadian Osteoporosis Di RSUD Embung Fatimah Kota Batam Tahun 2019

\begin{tabular}{|c|c|c|c|c|c|c|c|c|}
\hline \multirow[t]{3}{*}{ No } & \multirow{3}{*}{ Sikap } & \multicolumn{4}{|c|}{ Kejadian Osteoporosis } & \multicolumn{2}{|c|}{ Jumlah } & \multirow{3}{*}{$\begin{array}{c}\text { Nilai } \\
\text { P value }\end{array}$} \\
\hline & & \multicolumn{2}{|c|}{ Terjadi } & \multicolumn{2}{|c|}{ Tidak Terjadi } & & & \\
\hline & & $\mathbf{n}$ & $\%$ & $\mathbf{n}$ & $\%$ & $\mathbf{n}$ & $\%$ & \\
\hline 1. & Positif & 3 & 16,7 & 8 & 61,5 & 11 & 35,5 & 0,035 \\
\hline 2. & Netral & 8 & 61,5 & 3 & 16,7 & 11 & 35,5 & \\
\hline 3. & Negatif & 7 & 38,9 & 2 & 15,4 & 9 & 29 & \\
\hline & Jumlah & 18 & 58,1 & 13 & 41,9 & 31 & 100 & \\
\hline
\end{tabular}

Tabel 7 dapat diketahui bahwa dari 31 responden sebagian besar responden sikap positif tidak terjadi osteoporosis ada $61,5 \%$, hanya 16,7 yang terjadi dan sebagian besar responden sikap negatif terjadinya osteoporosis ada $61,5 \%$, hanya $16,7 \%$ yang tidak terjadi. Hasil uji statistik chi-square didapatkan nilai $\mathrm{p}$ value $0,035 \leq 0,05$ berarti dapat disimpulkan berarti dapat disimpulkan ada perbedaan proporsi sikap responden positif yang tidak terjadi osteoporosis dengan yang terjadi osteoporosis, artinya Ho ditolak dan Ha diterima, ada hubungan sikap responden terhadap kejadian osteoporosis di RSUD Embung Fatimah Kota Batam.

Tabel 8 Hubungan Gaya Hidup Dengan Kejadian Osteoporosis Di RSUD Embung Fatimah Kota Batam Tahun 2019

\begin{tabular}{|c|c|c|c|c|c|c|c|c|}
\hline \multirow[t]{3}{*}{ No } & \multirow{3}{*}{ Pengetahuan } & \multicolumn{4}{|c|}{ Kejadian Osteoporosis } & \multirow{2}{*}{\multicolumn{2}{|c|}{ Jumlah }} & \multirow{3}{*}{$\begin{array}{c}\text { Nilai } \\
\mathbf{p}\end{array}$} \\
\hline & & \multicolumn{2}{|c|}{ Terjadi } & \multicolumn{2}{|c|}{ Tidak Terjadi } & & & \\
\hline & & $\mathbf{n}$ & $\%$ & $\mathbf{N}$ & $\%$ & $\mathbf{n}$ & $\%$ & \\
\hline 1. & Sehat & 6 & 33,3 & 9 & 69,2 & 15 & $\begin{array}{r}48, \\
4\end{array}$ & 0,048 \\
\hline 2. & Tidak Sehat & 12 & 66,7 & 4 & 30,8 & 16 & $\begin{array}{r}51, \\
6\end{array}$ & \\
\hline & Jumlah & 18 & 58,1 & 13 & 41,9 & 31 & 100 & \\
\hline
\end{tabular}

Tabel 8 dapat diketahui bahwa dari 31 responden sebagian besar responden gaya hidup sehat tidak terjadi osteoporosis ada $69,2 \%$, hanya $33,3 \%$ yang terjadi dan sebagian besar responden gaya hdup tidak sehat terjadinya osteoporosis ada $66,7 \%$, hanya 30,8\% yang tidak terjadi. Hasil uji statistik chi-square didapatkan 
nilai p value $0,048 \leq 0,05$ berarti dapat disimpulkan berarti dapat disimpulkan ada perbedaan proporsi gaya hidup responden sehat yang tidak terjadi osteoporosis dengan yang terjadi osteoporosis, artinya Ho ditolak dan Ha diterima (ada hubungan gaya hidup responden terhadap kejadian osteoporosis di RSUD Embung Fatimah Kota Batam ).

Tabel 9. Determinan Pengetahuan, Sikap dan Gaya Hidup dengan Kejadian Osteoporosis Di RSUD Embung Fatimah Kota Batam Tahun 2019

\begin{tabular}{lcccccc}
\hline Model & R & R Square & Adjusted R Square & $\begin{array}{c}\text { Std. Error } \\
\text { of the } \\
\text { Estimate }\end{array}$ & F value \\
\hline 1 & $.558 \mathrm{a}$ & .312 & .235 & .439 & 4,073 & 0,016 \\
\hline
\end{tabular}

Tabel 9 diatas menunjukkan sub variabel pengetahuan, sikap dan gaya hidup berhubungan terhadap kejadian osteoporosis, hal ini di dibuktikan dengan nilai $\mathrm{F}$ signifikan 4,073 dengan $p$ value 0,016 .

\section{PEMBAHASAN}

\section{Hubungan Pengetahuan dengan Kejadian Osteoporosis}

Berdasarkan hasil penelitian dapat diketahui bahwa dari sebagian besar responden pengetahuan baik osteoporosis terjadi ada $0 \%$, hanya $23,1 \%$ yang tidak terjadi dan sebagian besar responden pengetahuan kurang terjadinya osteoporosis ada $69,6 \%$, hanya 30,4\% yang tidak terjadi. Hasil uji statistik chi-square didapatkan nilai $\mathrm{p}$ value $0,048 \leq 0,05$ berarti dapat disimpulkan berarti dapat disimpulkan ada perbedaan proporsi pengetahuan responden yang terjadi osteoporosis dengan yang tidak terjadi osteoporosis, artinya Ho ditolak dan Ha diterima (ada hubungan pengetahuan responden terhadap kejadian osteoporosis di RSUD Embung Fatimah Kota Batam ). Analisis keeratan hubungan dua variabel didapat $\mathrm{OR}=7,168$.

Hasil penelitian ini sesuai dengan pendapat Notoatmodjo (2007), yang menyatakan bahwa hubungan antara pengetahuan, sikap, niat dan perilaku akan mempengaruhi keikutsertaan seseorang didalam suatu aktifitas tertentu. Adanya pengetahuan terhadap manfaat sesuatu hal, akan menyebabkan orang mempunyai 
sikap yang positif terhadap hal tersebut. Pengetahuan berisikan segi positif dan negatif, bila sesuatu kegiatan dianggap lebih banyak segi positifnya, maka kemungkinan besar seseorang akan mengikuti kegiatan tersebut. Hasil penelitian ini sesuai dengan penelitian (Sudarmiati, 2012) tentang "hubungan antara pengetahuan dan sikap wanita premenopause dengan perilaku pencegahan osteoporosis". Hasil penelitian menunjukan bahwa wanita premenopause memiliki pengetahuan yang baik mengenai osteoporosis $(53,8 \%)$, sikap yang positif terhadap osteoporosis $(38,2 \%)$, dan perilaku yang aktif (57,5\%). Hasil dari analisa bivariat menunjukan bahwa ada hubungan pengetahuan wanita premenopause dengan perilaku pencegahan osteoporosis $(p$ value $=0,01)$ dan ada hubungan antara sikap wanita premenopause dengan perilaku pencegahan osteoporosis $(p$ value $=0,04)$.

Menurut asumsi peneliti pengetahuan wanita tentang osteoporosis mempuyai hubungan dengan kejadian osteoporosis, jika wanita mempunyai pengetahuan tentang osteoporosis yang baik maka akan mempengaruhi angka kejadian osteoporosis, dan jika wanita premenopause mempunyai pengetahuan yang cukup sedikit adanya dorongan atau keinginan yang positif, mempuyai harapan yang tinggi namun memiliki keyakinan yang rendah sehingga angka kejadian osteoporosis rendah.

\section{Hubungan Sikap dengan Kejadian Osteoporosis}

Berdasarkan hasil penelitian dapat diketahui bahwa sebagian besar responden sikap positif tidak terjadi osteoporosis ada $61,5 \%$, hanya 16,7 yang terjadi dan sebagian besar responden sikap negatif terjadinya osteoporosis ada $61,5 \%$, hanya $16,7 \%$ yang tidak terjadi. Hasil uji statistik chi-square didapatkan nilai $\mathrm{p}$ value $0,035 \leq 0,05$ berarti dapat disimpulkan ada perbedaan proporsi sikap responden positif yang tidak terjadi osteoporosis dengan yang terjadi osteoporosis, artinya Ho ditolak dan Ha diterima (ada hubungan sikap responden terhadap kejadian osteoporosis di RSUD Embung Fatimah Kota Batam ). Hal itu sesuai dengan penjelasan Allport (1954) yang di kutip Notoatmodjo (2015), bahwa sikap terdiri dari 3 komponen yaitu kepercayaan, kehidupan emosional, dan kecenderungan 
untuk bertindak. Ketiga komponen tadi bersama-sama membentuk sikap yang utuh dimana pengetahuan, pikiran, dan emosi memegang peranan penting. Akan tetapi pengetahuan dan sikap yang baik belum menentukan perilaku. Hal ini sesuai dengan yang telah di sampaikan Notoatmodjo (2015), bahwa perubahan perilaku atau seseorang menerima atau mengadopsi perilaku baru dalam kehidupannya melalui tiga tahap yaitu, pengetahuan, sikap dan praktek atau tindakan. Penelitian yang dilakukan oleh (Tandra, 2017) diperoleh bahwa dari 131 orang $(61,8 \%)$ yang memiliki sikap positif terdapat 86 orang $(40,7 \%)$ berperilaku aktif dan 45 orang $(21,2 \%)$ berperilaku pasif dan dari 81 orang $(38,2 \%)$ yang memiliki sikap negatif terdapat 36 orang $(16,9 \%)$ berperilaku aktif dan 45 orang $(21,2 \%)$ berperilaku pasif. Sehingga ada hubungan antara sikap dan perilaku wanita premenopause terhadap pencegahan osteoporosis. Menurut asumsi peneliti sikap responden yang positif dan netral dikarenakan sebagian sudah mendapatkan informasi tentang osteoporosis.

\section{Hubungan Gaya Hidup dengan Kejadian Osteoporosis}

Berdasarkan hasil penelitian dapat diketahui bahwa sebagian besar responden gaya hidup sehat tidak terjadi osteoporosis ada $69,2 \%$, hanya $33,3 \%$ yang terjadi dan sebagian besar responden gaya hidup tidak sehat terjadinya osteoporosis ada $66,7 \%$, hanya $30,8 \%$ yang tidak terjadi. Hasil uji statistik chi-square didapatkan nilai $\mathrm{p}$ value $0,048 \leq 0,05$ berarti dapat disimpulkan berarti dapat disimpulkan ada perbedaan proporsi gaya hidup responden sehat yang tidak terjadi osteoporosis dengan yang terjadi osteoporosis, artinya Ho ditolak dan Ha diterima (ada hubungan gaya hidup responden terhadap kejadian osteoporosis di RSUD Embung Fatimah Kota Batam). Pola makan yang kurang baik seperti kurang mengkonsumsi makanan yang kaya kalsium dan vitamin $\mathrm{D}$ dalam pola makan dapat berperan dalam osteoporosis. Makanan yang mengandung Kalsium merupakan nutrisi yang sangat penting bagi tulang agar menjadi lebih kuat. Wanita-wanita yang mengkonsumsi makanan yang rendah kalsium dan absorbsinya tidak baik, akan mengakibatkan keseimbangan kalsiumnya menjadi negatif, sedang mereka yang masukan kalsiumnya baik dan absorbsinya juga baik, menunjukkan keseimbangan kalsium positif. Sehingga diaharapkan adanya 
keseimbangan antara masukan kalsium dan absorbsi dalam meminimalkan risiko osteoporosis. Sejalan dengan penelitian yang dilakukan oleh Candra (2017) yang menunjukkan ada hubungan yang bermakna antara gaya hidup yang sehat seperti meminum susu kalsium, melakukan aktifitas fisik serta olahraga yang teratur akan meningkatkan kesehatan. Akan tetapi penelitian ini bertentangan dengan penelitian yang dilakukan oleh Baheiraei (2015) menyatakan tidak ada hubungan antara gaya hidup seperti aktifitas fisik olahraga yang teratur dengan kejadian osteoporosis, hal ini terjadi karena kuisioner yang digunakan hanya menggambarkan kondisi keadaan responden saat itu. Dan dimana hanya sedikit dari keseluruhan responden yang benar - benar melakukan aktifitas fisik \& olahraga yang teratur. Menurut asumsi peneliti gaya hidup wanita yang sehat sangat mempengaruhi resiko terjadinya osteoporosis pada wanita. Wanita yang kesehariannya melakukan gaya hidup yang sehat seperti minum susu kalsium, aktifitas fisik, berjemur dipagi dan sore, banyak minum air putih, menghindari minum obat pelangsing dan jamu yang tidak jelas serta melakukan olahraga yang teratur akan mengurangi atau bahkan tidak terjadinya osteoporosis pada wanita.

\section{SIMPULAN DAN SARAN}

\section{SIMPULAN}

a. Usia responden tertinggi adalah yang berusia lebih dari 45-50 tahun sebanyak 17 orang $(54,8 \%)$. Dengan responden tertinggi adalah tidak bekerja dengan jumlah 17 orang $(54,8 \%)$. Dalam penelitian ini, pendidikan responden tertinggi adalah SD sebanyak 15 responden (48,4\%).

b. Pengetahuan responden di RSUD Embung Fatimah tertinggi yaitu pengetahuan kurang sebanyak 23 orang $(74,2 \%)$ dan terendah yaitu penegtahuan baik adalah 3 orang $(9,7 \%)$.

c. Sikap responden di RSUD Embung Fatimah tertinggi yaitu sikap postif dan netral sebanyak 11 orang $(35,5 \%)$ dan terendah yaitu negatif adalah 9 orang $(29 \%)$.

d. Gaya hidup responden di RSUD Embung Fatimah tertinggi yaitu gaya hidup tidak sehat sebanyak 16 orang $(51,6 \%)$ dan terendah yaitu sehat adalah 15 orang $(48,4 \%)$.Hasil analisa didapatkan nilai $\mathrm{p}$ value $0,048 \leq 0,05$ berarti dapat 
disimpulkan berarti dapat disimpulkan ada perbedaan proporsi pengetahuan responden yang terjadi osteoporosis dengan yang tidak terjadi osteoporosis, artinya Ho ditolak dan Ha diterima (ada hubungan pengetahuan responden terhadap kejadian osteoporosis di RSUD Embung Fatimah Kota Batam ). Analisis keeratan hubungan dua variabel didapat $\mathrm{OR}=7,168$

e. Hasil analisa didapatkan nilai $\mathrm{p}$ value $0,035 \leq 0,05$ berarti dapat disimpulkan berarti dapat disimpulkan ada perbedaan proporsi sikap responden positif yang tidak terjadi osteoporosis dengan yang terjadi osteoporosis, artinya Ho ditolak dan Ha diterima (ada hubungan sikap responden terhadap kejadian osteoporosis di RSUD Embung Fatimah Kota Batam). Analisis keeratan hubungan dua variabel didapat $\mathrm{OR}=6,849$

f. Hasil analisa didapatkan nilai $\mathrm{p}$ value $0,048 \leq 0,05$ berarti dapat disimpulkan berarti dapat disimpulkan ada perbedaan proporsi gaya hidup responden sehat yang tidak terjadi osteoporosis dengan yang terjadi osteoporosis, artinya Ho ditolak dan Ha diterima (ada hubungan gaya hidup responden terhadap kejadian osteoporosis di RSUD Embung Fatimah Kota Batam ). Analisis keeratan hubungan dua variabel didapat $\mathrm{OR}=3,895$.

g. Dari hasil analisis diperoleh nilai koofisien determinan (Adjusted $R$ Square) $=$ 0,312 berarti 31,2\% faktor pengetahuan, sikap dan gaya hidup dapat dijelaskan terhadap kejadian osteoporosis.

\section{SARAN}

\section{a. Bagi Institusi Pendidikan STIKes Awal Bros Batam}

Diharapkan dapat menjadi materi dalam pelaksanaan pelayanan keperawatan tentang Faktor-faktor yang berhubungan dengan kejadian Osteoporosis pada wanita di RSUD Embung Fatimah Kota Batam.

\section{b. Bagi Manajemen Rumah Sakit RSUD Embung Fatimah Kota Batam}

Diharapkan dapat meningkatkan sosialisasi pada masyarakat mengenai osteoporosis pada wanita, Serta dapat memberikan informasi hasil penelitian ke pihak pemangku kebijakan agar dapat meningkatkan sosialisasi mengenai osteoporosis pada wanita seiring perkembangan banyaknya wanita terkena osteoporosis. 


\section{c. Bagi Peneliti Selanjutnya}

Diharapkan kepada peneliti selanjutnya untuk dapat mengembangkan dan melanjutkan penelitian ini pada penelitian yang lebih baik dengan meneliti Faktor-faktor yang berhubungan dengan pencegahan osteoporosis pada wanita di RSUD Embung Fatimah Kota Batam.

\section{DAFTAR RUJUKAN}

Amirullah. (2015). Populasi dan Sampel (Pemahaman, Jenis dan Teknik). Bayumedia Publishing Malang, 17(1993), 100-108. doi.org/10.1007/BF00353157

Annisa, N. N., Hidajat, N. N., \& Setiawati, E. P. (2019). Hubungan Pengetahuan dan Sikap dengan Tindakan Pencegahan Osteoporosis pada Remaja Puteri di Kecamatan Soreang Kabupaten Bandung. 4, 110-116.

B., Schrager, S., Dalby, J., Torell, E., \& Hampton, A. (2018). Primary Care Clinics in Office Practice. doi.org/10.1016/j.pop.2018.08.001

Cosman, F., de Beur, S. J., LeBoff, M. S., Lewiecki, E. M., Tanner, B., Randall, S., \& Lindsay, R. (2015). Erratum to: Clinician's guide to prevention and treatment of osteoporosis [Osteoporosis International, DOI:10.1007/s00198014-2794-2]. Osteoporosis International, 26(7), 2045-2047. doi.org/10.1007/s00198-015-3037-x

Dieny, F. F., \& Fitranti, D. Y. (2017). Faktor risiko osteoporosis pada wanita usia 40-80 tahun: Jurnal Gizi Klinik Indonesia. doi.org/10.22146/ijen.24872

Fallis, A. . (2015). Kinerja. Journal of Chemical Information and Modeling, 53(9), 1689-1699. doi.org/10.1017/CBO9781107415324.004

Harly Viani.2015.Gambaran Pengetahuan, Sikap dan Tindakan Pencegahan Osteoporosis Pada Wanita Usia Subur di Kelurahan Jati Makmur Kecamatan Binjai Utara Tahun 2015. USU. Medan

Karolina, M. S. (2015). Maha Sari Karolina: Hubungan Pengetahuan dan Kecamatan Medan Selayang, 2015. Pencegahan Osteoporosis yang Dilakukan Lansia.

Kemenkes. (2018). Kemenkes 2018.

Khoirullah. 2017.Hubungan Pengetahuan Wanita Usia Tentang Osteoporosis Premenopause Dengan Pencegahan Osteoporosis.STIKIMJ

Lestari, N. M. S. D. (2015). Latihan Fisik dan Osteoporosis Pada Wanita Universitas Pendidikan Ganesha. 
Lewiecki, E. M. (2019). Osteoporosis. In Metabolic Bone Diseases: A CaseBased Approach. doi.org/10.1007/978-3-030-03694-2

Lolang, E. (2015). ) yaitu hipotesis yang akan diuji. Biasanya, hipotesis ini merupakan pernyataan yang menunjukkan bahwa suatu parameter populasi memiliki nilai tertentu. (3), 685-696.

Puteri, M. D. (2016). Osteoporosis Dengan Upaya Pencegahan Osteoporosis Di Pundung Nogotirto.

Rajaratenam, S. G., Martini, R. D., \& Lipoeto, N. I. (2015). Hubungan Tingkat Pengetahuan dan Sikap dengan Tindakan Pencegahan Osteoporosis pada Wanita Usila di Kelurahan Jati. Jurnal Kesehatan Andalas, 3(2), 225-228. doi.org/10.25077/jka.v3i2.96

Rosi pratiwi. (2015). Rosi Pratiwifaktor-Faktor Yang Berhubungan Dengan Kejadian Osteoporosis Di Puskesmas Pondok Betung Tahun 2014. 1-111.

Sugiyono, P. D. (2015). Populasi dan sampel. Metode Penelitian Kuantitatif, Kualitatif Dan R\&D.

Syam, Y., Noersasongko, D., \& Sunaryo, H. (2015). Fraktur Akibat Osteoporosis. E-CliniC, 2(2). doi.org/10.35790/ec1.2.2.2014.4885

Taradita, W., ... R. R.-J. K., \& 2018, U. (2018). Hubungan Tingkat Osteoporosis Berdasarkan Indeks Singh dan Fraktur Leher Femur Akibat Low Energy Trauma di Beberapa Rumah Sakit di Padang Tahun 2016-2018. Jurnal.Fk.Unand.Ac.Id, 7(2), 226-232. Retrieved from http://jurnal.fk.unand.ac.id/index.php/jka/article/view/806

Tuegeh, J., Oeitono, A., \& Tangka, J. (2015). Hubungan Pengetahuan Wanita Dengan Pencegahan Dini Osteoporosis Di Poliklinik Rhematologi BLU RSUP Prof. Dr. R.D. Kandou Manado. Jurnal Ilmiah Perawat Manado, 1(1), 92664.

Underprivileg, A., Motivation, M., Prodigies, I., Children, T., \& Day, P. (2019). November 2019. (November), 16-18.

Widoyoko, Eko. 2016. Teknik Penyusunan Instrumen Penelitian. Yogyakarta: Pustaka Pelajar.

Yedavally-Yellayi, S., Ho, A. M., \& Patalinghug, E. M. (2019). Update on Osteoporosis. Primary Care - Clinics in Office Practice, 46(1), 175-190. doi.org/10.1016/j.pop.2018.10.014

Yusup, F. (2018). Uji Validitas dan Reliabilitas Instrumen Penelitian Kuantitatif. Jurnal Tarbiyah: Jurnal Ilmiah Kependidikan. doi.org/10.18592/tarbiyah.v7i1.2100 